Susan D. Herring, Robert R. Burkhardt, Jennifer L. Wolfe

Reaching remote students

Athens State University's electronically embedded librarian program

$\mathbf{H}^{\circ}$ ow can we teach library skills and information awareness to students who don't come to the library? This has long been a problem for academic librarians, but it has become even more troublesome with distance learning. What can we do for students who never come to campus, let alone to the library? For the librarians at Athens State University, this question has led to a successful venture into the electronic delivery of library assistance through the electronically embedded librarian program.

The concept of the embedded librarian is not new. College and university librarians have traditionally spent time with classes, either in instructional sessions or as team teachers. However, these outreach programs assume that students and faculty are actually on site. Library Web sites can provide a partial answer for off-site students, providing access to resources, instructional materials such as tutorials and handouts, and online assistance through a virtual reference desk. However, as Amy York writes, "Library websites are useful for helping students who know what they are looking for, but online students need an equivalent of the reference desk when they are just getting started with research." So the question remains: How do we reach remote clientele?

Course management systems (CMS) such as Blackboard and WebCT can provide the answer. CMS provide a convenient, focused environment in which relevant library resources can be selected and organized for specific classes in an easily accessed interface. ${ }^{2}$ In addition, the CMS provides a structure in which a librarian can become part of the course. By including the librarian as a teaching assistant, students and faculty have immediate access to library assistance, advice, suggestions, and resources. As Shumaker and Tyler have written, "Academic embedded librarians are finding innovative approaches that employ electronic resources, moving services beyond 'bibliographic instruction' and 'information literacy."'3 Kelly, writing from the instructor's viewpoint, reports that students are more willing to seek help when they know a librarian is an integral part of the class. ${ }^{4}$

Early examples of institutions using a CMS as a tool for library instruction include Central Missouri State University ${ }^{5}$ and the University of Rhode Island. ${ }^{6}$ Middle Tennessee State University instituted an embedded librarian program in 2004, which has proven to be very popular with both students and faculty members. ${ }^{7}$

\section{Athens State University}

Athens State University is an upper-division two-year institution, providing courses for

Susan D. Herring is cataloger/reference librarian, e-mail: susan.herring@athens.edu, Robert R. Burkhardt is library director, e-mail: robert.burkhardt@athens.edu, and Jennifer L. Wolfe is head of circulation/reference librarian, e-mail: jennifer.wolfe@athens.edu, at Athens State University

๑ 2009 Susan D. Herring, Robert R. Burkhardt, and Jennifer L. Wolfe 
junior- and senior-level students only, leading to the bachelor's degree with majors in business, education, and arts and sciences. The majority of the student body has transferred from community colleges, works full-time, and has family responsibilities. Because Athens State is an upper-division institution, faculty and librarians do not have the chance to ensure that students gain a good grounding in information literacy in their first two years in college.

Athens State has been involved in distance learning since the late 1990s and currently offers courses through Web-based delivery; traditional face-to-face classes on site and at remote centers; and "blended" classes, which combine face-to-face and distance delivery methods. All classes, regardless of format, use Blackboard for either primary or supplementary content delivery.

With the increasing number of distance classes, and increasing number of students who never come to the campus, library use has changed. Although foot traffic is down, use of online resources has increased. Still, anecdotal evidence, as well as library surveys and focus groups, indicate that many students were not aware of library services. In the fall term of 2007, we decided to reach out proactively through an electronically embedded librarian program.

\section{The electronically embedded librarian program}

In the electronically embedded librarian program at Athens State, specific classes are selected for the service either at the request of the course instructor or the suggestion of the library director or college dean. Classes with a formal research component (a research paper or presentation) are preferred. As classes are identified, a reference librarian is assigned to each one and is designated as a teaching assistant (TA) in the Blackboard package for that class.

As a TA, the librarian has access to the course syllabus, the class list, all assignments and course materials, and all communication tools, and has authority to post materials to the class site. Standard activities for the embedded librarians include:

- Introductory announcements and/or e-mails to students. With the approval of the instructor, the embedded librarian posts an announcement of the service and/or sends an e-mail to all students in the class, introducing himself or herself and explaining the purpose and limitations of the embedded librarian program. At this point students are also told how to contact the librarian.

- Creation of an "Ask Your Librarian" discussion forum. Most classes have discussion forums set up at the beginning of the term where students can ask questions concerning research, library resources, proper citation style, and other library and research-related issues.

- Creation and posting of instructional documents. These may be either general handouts, such as how to access e-books or how to identify a scholarly journal, or handouts that are specific to the area of study or the class. Informational slide shows can also be posted.

- Creation and posting of video instruction sessions. Video sessions can be useful to demonstrate research methods and techniques, such as searching in online databases and evaluating Web sites. Although creation of these recordings requires training and can involve significant time for preparation and production, they can be highly effective. Athens State uses the Tegrity program, but any program that permits live screen captures and that is compatible with the institution's instructional technology system can be used.

- Assistance through the discussion forum, phone, and e-mail queries. The most time-consuming part of the embedded librarian program is the daily involvement in each class. Students expect rapid responses to their queries, so discussion forums should be checked at least once a day. Students also phone, e-mail, and drop by the library for personal assistance.

Other embedded librarian activities have included involvement in blogs and wikis, research for instructors, and face-to-face instruc- 
tion for classes that have an on-site component and for students who travel to campus.

\section{Success of the embedded librarian program}

Involvement in the embedded librarian program has increased from three librarians handling 11 classes in fall 2007 to four librarians handling 64 classes in the spring of 2009 (see Table 1).
Perhaps the most obvious, and rewarding, outcome of the program is a significant increase in communication with students. Some classes use the discussion forum much more than others, but even in classes where few students post questions, numerous queries are received through e-mail and telephone, and students will come to campus specifically for research help. Many students continue their communication with the embedded librarian

Table 1. Growth of the Program

\begin{tabular}{|l|c|c|c|c|c|}
\hline & Fall 2007 & Spring 2008 & Summer 2008 & Fall 2008 & Spring 2009 \\
\hline Classes & 11 & 22 & 32 & 59 & 64 \\
\hline Libraries & 3 & 4 & 4 & 4 & 4 \\
\hline
\end{tabular}

Although the program was originally designed as an outreach program for distance classes, it has been used in classes delivered through all methods available at Athens State. Distance and off-site classes, combined, have comprised $59.6 \%$ of the total classes involved in the program, while onsite classes have comprised 30.3\%. Blended classes account for the remaining 10.1\%.

The embedded librarian program at Athens State was originally spearheaded by the library director, who serves as liaison with the College of Arts and Sciences, and the reference librarian who is liaison to the College of Business. These disciplines are reflected in the use of the program during the first two semesters (see Table 2). The College of Business has a library component in the required Organizational Communication class, and the embedded librarian was quickly added to all sections of that class. The sudden expansion of the program into the College of Education in the summer of 2008 occurred when a similar library component was added to the required Foundations of Education class.

Table 2. Classes by College in subsequent semesters. They also refer other students to "their" librarian for assistance. Such continuing communication can help ease library anxiety and can build a more personal and friendly relationship between students and the library.

\section{Lessons learned}

After offering the electronically embedded librarian program for over a year, we have learned a number of lessons for making the program successful. These include:

- Use different tools to reach different types of learners. Some students are fine with printed instructions; some need the visual presentations or oral explanations that come with video recordings; others need the face-to-face learning environment of the library. The embedded librarian must be prepared to present information in whatever mode is required.

- Be ready to use different forms of communication. Some students are happy to post questions to a discussion board, but this type of public forum makes others feel exposed and embarrassed. Be prepared to be contacted in a variety of ways.

\begin{tabular}{|l|c|c|c|c|c|}
\hline & Fall 2007 & Spring 2008 & Summer 2008 & Fall 2008 & Spring 2009 \\
\hline $\begin{array}{l}\text { Arts and } \\
\text { Sciences }\end{array}$ & 4 & 8 & 2 & 12 & 13 \\
\hline Business & 6 & 14 & 14 & 29 & 31 \\
\hline Education & 1 & 0 & 16 & 18 & 20 \\
\hline
\end{tabular}


- Set limits. Make it clear that the embedded librarian is a resource person and teacher and is not there to do the student's work. Sometimes requests for answers or materials (such as "I need three articles on this topic. Can you find them for me?") can be dealt with simply by providing guidance in the use of resources; other times these limits must be made explicit, either by the librarian or the instructor.

- Make sure the faculty member supports and encourages student use of the program. Faculty support is a prerequisite for the success of the embedded librarian program. Each faculty member must want the librarian to be involved and must encourage students to make use of him or her.

The librarian will need to negotiate a balance between librarian and instructor regarding preparing and posting materials, contacting students, and determining the level of help to provide.

In addition to these lessons that directly concern the embedded librarian program, this close involvement in courses has made us realize that we need to augment our library Web site with additional instructional offerings, and to enhance information literacy instruction across the curriculum.

\section{Into the future}

At Athens State, we intend to continue offering the embedded librarian program. With a small professional staff, we are reaching the limit of our resources, so we plan to focus more on classes with a formal research component. To alleviate some of the stress on our librarians, we are trying to share more tools and resources.

For example, we have created some handouts and video recordings that can be used across multiple subject areas. This allows the librarians to focus more on specialized materials rather than spending time and effort re-creating general tools.

Along with some of the faculty using the embedded librarian program, we intend to explore the use of blogs and wikis, both of which can serve as useful communication and instructional tools. We also plan to help each other expand our repertoire of instructional methodologies. Not all of us are equally comfortable with the various methodologies available.

The electronically embedded librarian program reflects the current paradigm shift in the academic environment that has evolved from the combination of new technologies and a new generation of students. Libraries, and their institutions, need to be ready and able to provide support and services for this new generation of students who expect access to all resources-human and otherwise-anytime, anywhere.

By joining these students in their learning environment, we can begin to give them the tools and services they need and deserve.

\section{Notes}

1. Amy York, "The Embedded Librarian Service at MTSU," Tennessee Libraries 56.2 (2006), www.tnla.org/displaycommoncfm ?an=1\&subarticlenbr=65.

2. Scott Collard and Nadaleen TempelmanKluit, "The Other Way In: Goal-based Library Content Through CMS," Internet Reference Services Quarterly 11, no. 4 (October 2006): 55-68, in the Professional Development Collection database.

3. David Shumaker and Laura Ann Tyler, "Embedded Library Services: An Initial Inquiry into Practices for Their Development, Management, and Delivery," (paper presented at the Special Libraries Association Annual Conference in Denver, June 6, 2007).

4. Rob Kelly, "Team Teaching with an Embedded Librarian," Online Classroom (October 2008): 7-8, in the Professional Development Collection database.

5. Mollie Dinwiddie, "Looking for Ways to Provide Online Library Services Equal to Oncampus." Distance Education Report 9, no. 18 (September 15, 2005): 8-8, in the Professional Development Collection database.

6. Karen M. Ramsay and Jim Kinnie, "The Embedded Librarian: Getting Out There via Technology to Help Students Where They Learn," Library Journal (April 1, 2006): 34-35.

7. York, 3. $n$ 